\title{
Investigation of the levels of circulating miR-29a, miR-122, sestrin 2 and inflammatory markers in obese children with/without type 2 diabetes: a case control study
}

\author{
Khalid M. Mohany ${ }^{1,2^{*}}$, Osamah Al Rugaie ${ }^{2}$, Osama Al-Wutayd ${ }^{3}$ and Abdullah Al-Nafeesah ${ }^{4}$
}

\begin{abstract}
Aim: The present work investigated serum levels of miR-29a, miR-122 and sestrin2 in obese children with/without type-2-diabetes mellitus (T2DM), and their correlations with inflammatory, metabolic and anthropometric parameters.

Methods: The study included 298 children, divided into: G1 (control, $n=136$ ), G2 (obese without diabetes, $n=90$ ) and G3 (obese with T2DM, $n=72$ ). Metabolic and anthropometric parameters, miR-29a, miR-122 relative expressions, and sestrin2, high sensitivity C-reactive protein (hsCRP), interleukin-6 (IL-6), and tumor necrosis factor-a (TNF-a) levels were measured by their specific methods. The data was processed and analyzed by SPSS V.26 using the corresponding tests. After testing the variables' normality, Kruskal-Wallis one-way-ANOVA, Spearman correlations coefficient were used.

Results: Significant higher serum miR-29a, miR-122, IL-6, hsCRP and TNF- $a$ and lower sestrin2 levels were found in G2 and G3 than G1 and in G3 than G2 ( $p=>0.001$ for all). Especially in G3, miR-29a and miR-122 levels correlated positively while sestrin2 levels correlated negatively with waist circumference and BMI percentiles, serum levels of LDL-cholesterol, triacylglycerol, total cholesterol, HbA1c\%, glucose, insulin, c-peptide, homeostatic model assessment-insulin resistance (HOMA-IR), IL-6, hsCRP and TNF-a.

Conclusion: The change in the serum miR-29a, miR-122 and sestrin2 levels in obese children with/without T2DM may suggest a possible role of these biomarkers in the pathogenesis of childhood obesity and their accompanied complications e.g. inflammations and T2DM. Also, further studies are required to test drugs that antagonize the action miR-29a and miR-122 or upregulate sestrin2 in the management of these cases.
\end{abstract}

Keywords: MiR-29a, miR-122, Sestrin 2, Childhood obesity, T2DM

\footnotetext{
* Correspondence: khalidmohany@aun.edu.eg

'Department of Medical Biochemistry, College of Medicine, Assiut University, P.O. Box, Assiut 71515, Egypt

${ }^{2}$ Department of Basic Medical Sciences, Unaizah College of Medicine and Medical Sciences, Qassim University, Unaizah, Saudi Arabia

Full list of author information is available at the end of the article
}

(c) The Author(s). 2021 Open Access This article is licensed under a Creative Commons Attribution 4.0 International License, which permits use, sharing, adaptation, distribution and reproduction in any medium or format, as long as you give appropriate credit to the original author(s) and the source, provide a link to the Creative Commons licence, and indicate if changes were made. The images or other third party material in this article are included in the article's Creative Commons licence, unless indicated otherwise in a credit line to the material. If material is not included in the article's Creative Commons licence and your intended use is not permitted by statutory regulation or exceeds the permitted use, you will need to obtain permission directly from the copyright holder. To view a copy of this licence, visit http://creativecommons.org/licenses/by/4.0/. The Creative Commons Public Domain Dedication waiver (http://creativecommons.org/publicdomain/zero/1.0/) applies to the data made available in this article, unless otherwise stated in a credit line to the data. 


\section{Introduction}

Globally, the prevalence of childhood and adolescence obesity has increased markedly in the last decade $[1,2]$. About 30\% of Saudi Arabia children were reported to be obese or overweight [3, 4]. Obese children have a high risk of developing many cardiac and metabolic complications such as type 2 diabetes mellitus (T2DM) either during their childhood or, later during their adulthood $[5,6]$.

Indeed, both obesity and T2DM are considered as systemic inflammatory conditions $[7,8]$. Obesity is associated with dysregulation in the adipocyte-derived cytokines that leads to a generalized low inflammatory condition and insulin resistance $[9,10]$. In this regard, many previous studies were conducted to understand the pathogenesis of the obesity accompanied inflammations in order to prevent, control and manage them [7$10]$.

MicroRNAs (miRs) are short non-coding sequences of nucleotides that can modulate the process of adipogenesis and many of its related consequences [11]. Abnormal expressions of microRNAs have been reported by many previous studies in obese individuals with/without diabetes $[5,12]$. Of these microRNAs, miR-29a was found to correlate with insulin resistance and inflammatory parameters in obese adults with/without T2DM [13-15]. Also, miR-122 has been considered a good marker for obesity and its related complications. It correlated positively with insulin resistance in subjects without diabetes $[16,17]$.

Sestrin2 is an inducible protein that guards the cell from stress injury and keeps up optimum cell functions, metabolism, and endurance [18]. A decline in the cellular level of sestrin 2 is associated with oxidative damage, mitochondrial dysfunction, impaired glucose tolerance and diabetes mellitus [18]. The investigations of sestrin2 levels in patients with metabolic syndrome (e.g. obesity with/without T2DM) have revealed controversial results [18-20].

As many of the previous studies have tested the levels of miR-29a, miR-122 and sestrin 2 mainly in adults and some of their results were controversial, the present work aimed to measure these levels in obese children with/without T2DM and compared them to those of healthy non-obese controls. In addition, it investigated the correlation of these levels with various inflammatory, metabolic and anthropometric parameters.

\section{Subjects and methods}

About 1415 consecutive children who visited the primary health care units in Unaizah governorate, Qassim area, Saudi Arabia between January and August 2019 approached for participation in the present study. A number of 1117 of them were excluded according to the exclusion criteria mentioned later. The eligible children were 298; 195 males (65.5\%) and 103 females (34.5\%), their ages were 9 to 15 years. All the study participants' parents were acquainted with the study aim and gave a written informed consent. Medical histories were collected and examinations were done for all children. The children's waist circumference (WC) and body mass index (BMI) percentiles were calculated and the child was considered obese when his/her $\mathrm{WC} \geq 90$ th percentile and BMI $\geq 95$ percentile for age and sex [3]. The participants were divided into three groups; G1 (non-obese healthy control group, $n=136$ ), G2 (obese without diabetes group, $n=90$ ) and G3 (obese with T2DM, $n=72$ ). Diagnostic criteria of cases with T2DM included a random plasma blood glucose $\geq 200 \mathrm{mg} / \mathrm{dl}$, or fasting blood glucose of $\geq 126 \mathrm{mg} / \mathrm{dl}$, or oral glucose tolerance test with blood sugar $\geq 200 \mathrm{mg} / \mathrm{dl}$ hours post ingestion, or glycosylated hemoglobin percentage $(\mathrm{HbA} 1 \mathrm{c} \%)>6.5 \%$ [21].

The G3 participants had been managed only by lifestyle adjustments (those who had received any drug interventions were excluded from the study). Also, exclusion criteria included those who presented with T1DM, genetic or endocrinal disorders, inflammatory, or any other systemic illness [12].

\section{Sampling and laboratory analysis}

Five $\mathrm{ml}$ of fasting blood samples were withdrawn from all children. One $\mathrm{ml}$ was used to measure $\mathrm{HbA} 1 \mathrm{c} \%$ in the whole blood by glycated hemoglobin kit (Sigma-Aldrich, St. Louis, MO, USA). The remaining portion was left to be clotted then centrifuged for $10 \mathrm{~min}$ at 3000 $\mathrm{rpm}$ and the sera were collected in aliquots and stored at $-80{ }^{\circ} \mathrm{C}$ till the assay. Fasting serum glucose levels were measured by glucose oxidase activity assay kit (Colorimetric) (abcam Cat\# ab219924). Colorimetric methods were used to estimate serum total cholesterol (Spectrum Diagnostic Egypt, Cat\# 230003), HDL-C (Spectrum Diagnostic Egypt, Cat\# 266002), serum triacylglycerol (Spectrum Diagnostic Egypt, Cat\# 314003). LDL-C was estimated by Friedewald formula [22]. Insulin levels were measured by electrochemiluminescence assay and C-peptide was measured by human C-Peptide quantikine enzyme-linked immunosorbent assay (ELISA Kit DICP00, R\&D systems). Homeostasis model assessment of insulin resistance (HOMA-IR) was calculated after Matthew et al. [23].

The levels of sestrin 2 in the serum were assessed by the sestrin 2 ELISA method (MYBIOSOURCE, San Diego, CA 92195-3308, USA, \# MBS2024978) with detection range between $0.15 \mathrm{ng} / \mathrm{ml}-10 \mathrm{ng} / \mathrm{ml}$. Human interleukin-6 (IL-6) Solid Phase Sandwich ELISAKit (R\&D systems) was used to measure serum IL-6 levels with assay range b $0.2-10 \mathrm{pg} / \mathrm{ml}$. A latex-enhanced 
immunoturbidimetric assay (Diazyme Laboratories, 12,889 Gregg Ct, Poway, CA 92064, USA, Cataloge\# DZ135A-K) was used to measure the high-sensitivity Creactive protein (hsCRP) with detection range $0.20-20$ $\mathrm{mg} / \mathrm{l}$. The TNF $\alpha$ levels were measured by ELISA consistent with the accompanied protocol (Quantikine ELISA Kit R\&D Systems, Minneapolis, MN, USA).

\section{RNA extraction}

Circulating miRNAs were isolated and purified using miRNeasy kit (ThermoFisher scientific, Ambion ${ }^{\circledR}$ PureLink $^{\oplus}$ miRNA Isolation Kit, USA, Cat\# K157001). Briefly, the sera were centrifuged in a spin cartridge for $1 \mathrm{~min}$ at $12000 \mathrm{rpm}$. Ethanol (96-100\%) was added and mixed to the flow through to a final concentration of $70 \%$. Then, $500 \mu \mathrm{L}$ sample was transferred to a second spin cartridge and centrifuged again for $1 \mathrm{~min}$ at $12000 \mathrm{rpm}$. The miRNAs were bound to spine cartilage while the flow through was discarded. The spin cartridge was then washed with $500 \mu \mathrm{L}$ wash buffer mixed with ethanol

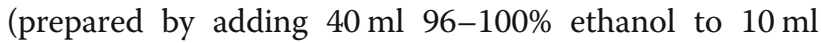
wash buffer) then centrifuged for $1 \mathrm{~min}$ at $12000 \mathrm{rpm}$ (this step was repeated once). The spin cartridge was then centrifuged at the maximum speed for $1 \mathrm{~min}$ to eliminate any residual wash buffer. The miRNAs were eluted with 50-100 $\mu \mathrm{L}$ RNase-free water then incubated at room temperature for $1 \mathrm{~min}$. The purified miRNAs were stored at $-80^{\circ} \mathrm{C}$ till being used [24].

\section{Complementary DNA (cDNA)}

Reverse transcription was done cDNA RT Kit (Applied Biosystems, Foster City, CA, USA, Cat. No: 438814) according to the manufacturers'. The miScript HiSpec Buffer was used. The samples were diluted with RNase-free water to even out the total amount of RNA. Twenty $\mu \mathrm{L}$ reverse transcription reaction, $8 \mu \mathrm{L}$ of the master mix, $12 \mu \mathrm{L}$ of RNA template and RNase-free were mixed in $0.2 \mathrm{ml} \mathrm{PCR}$ tubes and incubated at $37^{\circ} \mathrm{C}$ for sixty minutes then at $95^{\circ} \mathrm{C}$ for five minutes in thermal cycler (Applied Biosystems).

\section{Real time polymerase chain reaction (qRT-PCR)}

It was done using TaqMan ${ }^{\circledR}$ MiR RT Kit (Applied Biosystems, Foster City, CA, USA). Two and half $\mu \mathrm{L}$ universal master mix, $0.25 \mu \mathrm{L}$ primer and probe set, $0.33 \mu \mathrm{L}$ cDNA, and $1.92 \mu \mathrm{L} \mathrm{H} \mathrm{H}_{2} \mathrm{O}$ were mixed to make a $5 \mu \mathrm{L}$ reaction volume. qRT-PCR was done at $50{ }^{\circ} \mathrm{C}$ for $2 \mathrm{~min}$ and $95^{\circ} \mathrm{C}$ for $10 \mathrm{~min}$, followed by 40 cycles at $95^{\circ} \mathrm{C}$ for $15 \mathrm{~s}$ and $60^{\circ} \mathrm{C}$ for $1 \mathrm{~min}$. The cel-miR-39 was used as an internal control during the quantification using specific stem-loop primers for miR-29a and miR-122 [5, 12].

The analysis of the results was performed using Sequence Detection Software version 2.3 (Applied Biosystems). The difference in the expression levels of miR-29a and miR-122 between samples was calculated using the $2^{-\Delta \Delta C T}$ method $[5,12]$.

\section{Statistical analysis}

The collected data was analyzed by SPSS (v26). The Shapiro-Wilk test was used to evaluate the normality of continuous variables. Kruskal-Wallis one-way-ANOVA was used to compare them among the three studied groups. The correlations between different studied continuous variables levels were tested by Spearman's correlations coefficient. A 2-tailed $p<0.05$ was considered statistically significant.

\section{Results}

Comparison of different variables in the 3 studied groups The current study found significant high levels of miR29a, miR-122, IL-6, hsCRP and TNF- $\alpha$ in obese (G2) and obese with T2DM (G3) groups compared to the control (G1) group (Table 1) and in obese with T2DM (G3) group compared to obese (G2) group. On the other hand, the levels of sestrin 2 were significantly low in obese (G2) and obese with T2DM (G3) groups compared to the control (G1) group and in obese with T2DM (G3) group compared to obese (G2) group (Table 1).

\section{Correlations analysis In the whole sample}

The serum levels of miR-29a, miR-122, hsCRP, IL-6 and TNF- $\alpha$ correlated positively, while serum sestrin 2 levels correlated negatively with WC percentiles and BMI percentiles, and serum levels of LDL-cholesterol, triacylglycerols, $\mathrm{HbA} 1 \mathrm{c} \%$, glucose, insulin, c-peptide and with HOMA-IR. Also, the serum miR-29a and miR-122 levels correlated positively with each other (Fig. 1A) and with serum hsCRP, IL- 6 and TNF- $\alpha$ levels while correlated negatively with serum sestrin2 levels (Table 2, Fig. 2A and B). On the other hand, serum sestrin2 levels correlated negatively with serum levels of hsCRP, IL-6 and TNF- $\alpha$ (Table 2).

\section{In control group (G1)}

The serum levels of miR-29a correlated positively with serum levels of LDL-cholesterol, triacylglycerols, cholesterol, HbA1c\%, glucose, and insulin (Table 3). Its correlations with the serum levels of miR-122 and sestrin2 were non-significant (Figs. $1 \mathrm{~B}$ and $2 \mathrm{C}$ ). The serum levels of miR-122 correlated positively with WC percentiles and BMI percentiles and with serum insulin levels while negatively correlated with HDL-cholesterol levels (Table $3)$. Its correlation with serum sestrin2 levels was nonsignificant (Fig. 2D). Serum sestrin2 levels correlated positively with HDL-cholesterol. The serum levels of hsCRP correlated positively with BMI percentile and 
Table 1 Comparison of different variables among G1, G2 and G3

\begin{tabular}{|c|c|c|c|c|}
\hline & & $\begin{array}{l}\text { Healthy control group } \\
(\mathrm{G} 1 ; \mathrm{n}=136)\end{array}$ & $\begin{array}{l}\text { Obese group } \\
(\mathrm{G} 2 ; \mathrm{n}=90)\end{array}$ & $\begin{array}{l}\text { Obese with type } 2 \text { diabetes group } \\
(\mathrm{G} 3 ; n=72)\end{array}$ \\
\hline \multirow{2}{*}{$\begin{array}{l}\text { Gender } \\
\text { n (\%) }\end{array}$} & Male & $88(64.7 \%)$ & $62(68.9 \%)$ & $45(62.5 \%)^{\mathbf{a}}{ }^{9}$ ? \\
\hline & Female & $48(35.3 \%)$ & $28(31.1 \%)$ & $27(37.5 \%)^{a}{ }^{a}$ \\
\hline \multicolumn{2}{|c|}{ Age (years) } & $12.1 \pm 1.3$ & $12.2 \pm 1.4$ & $12.2 \pm 1.2^{\pi}$ \\
\hline \multicolumn{2}{|c|}{ WC percentile } & $72.3 \pm 7.2$ & $95.9 \pm 2.9$ & $96.1 \pm 2.9^{*}$ \\
\hline \multicolumn{2}{|c|}{ BMI percentile } & $79.1 \pm 6.8$ & $96.8 \pm 1.5$ & $96.7 \pm 1.4^{*}$ \\
\hline \multicolumn{2}{|c|}{ HDL-c (mg/dl) } & $41.2 \pm 2.9$ & $35.7 \pm 8.5$ & $34.0 \pm 9.5^{*}$ \\
\hline \multicolumn{2}{|c|}{ LDL-c (mg/dl) } & $120.4 \pm 21.4$ & $126.1 \pm 25.6$ & $132.4 \pm 17.0$ \\
\hline \multicolumn{2}{|c|}{ TAG (mg/dl) } & $107.8 \pm 19.6$ & $112.7 \pm 21.3$ & $142.4 \pm 37.1$ \\
\hline \multicolumn{2}{|c|}{ Cholesterol (mg/dl) } & $183.2 \pm 21.6$ & $184.4 \pm 26.6$ & $194.9 \pm 21.1$ \\
\hline \multicolumn{2}{|c|}{ Glucose (mg/dl) } & $81.7 \pm 12.7$ & $96.8 \pm 20.6$ & $106.5 \pm 25.7^{\#}$ \\
\hline \multicolumn{2}{|c|}{ HbA1c (\%) } & $4.4 \pm 0.7$ & $6.0 \pm 1.8$ & $7.9 \pm 1.9^{\#}$ \\
\hline \multicolumn{2}{|c|}{ Insulin ( $\mu \mathrm{g} / \mathrm{ml})$} & $7.6 \pm 1.7$ & $10.2 \pm 0.7$ & $10.6 \pm 1.2^{*}$ \\
\hline \multicolumn{2}{|c|}{ C-Peptide (ng/ml) } & $2.8 \pm 0.4$ & $3.0 \pm 0.3$ & $3.1 \pm 0.3 *$ \\
\hline \multicolumn{2}{|c|}{ HOMA-IR } & $1.5 \pm 0.4$ & $2.4 \pm 0.5$ & $2.8 \pm 0.6^{\#}$ \\
\hline \multicolumn{2}{|c|}{ miR-29a R } & $1.5 \pm 0.3$ & $1.9 \pm 0.2$ & $2.3 \pm 0.3^{\#}$ \\
\hline \multicolumn{2}{|c|}{ miR-122 R } & $1.6 \pm 0.3$ & $1.9 \pm 0.6$ & $2.6 \pm 0.9^{\#}$ \\
\hline \multicolumn{2}{|c|}{ Sestrin2 (ng/mL) } & $5.8 \pm 1.8$ & $4.1 \pm 2.6$ & $2.9 \pm 1.4^{\#}$ \\
\hline \multicolumn{2}{|c|}{ hsCRP (mg/dl) } & $0.8 \pm 0.1$ & $1.3 \pm 0.1$ & $1.4 \pm 0.2^{\#}$ \\
\hline \multicolumn{2}{|c|}{ IL-6 (pg/ml) } & $1.8 \pm 0.4$ & $2.2 \pm 0.8$ & $2.7 \pm 1.1^{\#}$ \\
\hline \multicolumn{2}{|c|}{ TNF-a (pg/ml) } & $1.1 \pm 0.2$ & $1.3 \pm 0.1$ & $1.6 \pm 0.6^{\#}$ \\
\hline
\end{tabular}

Unless otherwise indicated, the data is presented as mean \pm Standard deviation

WC: waist circumference, BMI: body mass index, HDL-c: high density lipoprotein cholesterol, LDL-c: low density lipoprotein cholesterol, TAG: triacylglycerol, HbA1c: glycosylated hemoglobin, HOMA-IR: Homeostatic model Assessment-Insulin resistance, miR-29a R: microRNA-29a relative expression, miR-122 R: microRNA-122 relative expression, hsCRP: high-sensitivity C-reactive protein, IL-6: interleukin 6, TNF-a: tumor necrosis factor alpha

${ }^{\text {a Chi-square }}$

" the p-values of G1 Vs. G2 Vs. G3, G1 Vs. G2, G1 Vs. G3 and G2 Vs. G3 were non-significant

* the $p$-values of G1 Vs. G2 Vs. G3, G1 Vs. G2, and G1 Vs. G3 were > 0.001 while G2 Vs. G3 were non-significant

\# the p-values of G1 Vs. G2 Vs. G3, G1 Vs. G2, G1 Vs. G3 and G2 Vs. G3 were $>0.001$

"the p-values of G1 Vs. G2 Vs. G3, G1 Vs. G2, G1 Vs. G3 and G2 Vs. G3 were $(0.01,0.02,0.009$ and 0.44 , respectively)

The p-values of G1 Vs. G2 Vs. G3 for LDL-c (0.06), TAG (> 0.001) and Cholesterol (non-significant
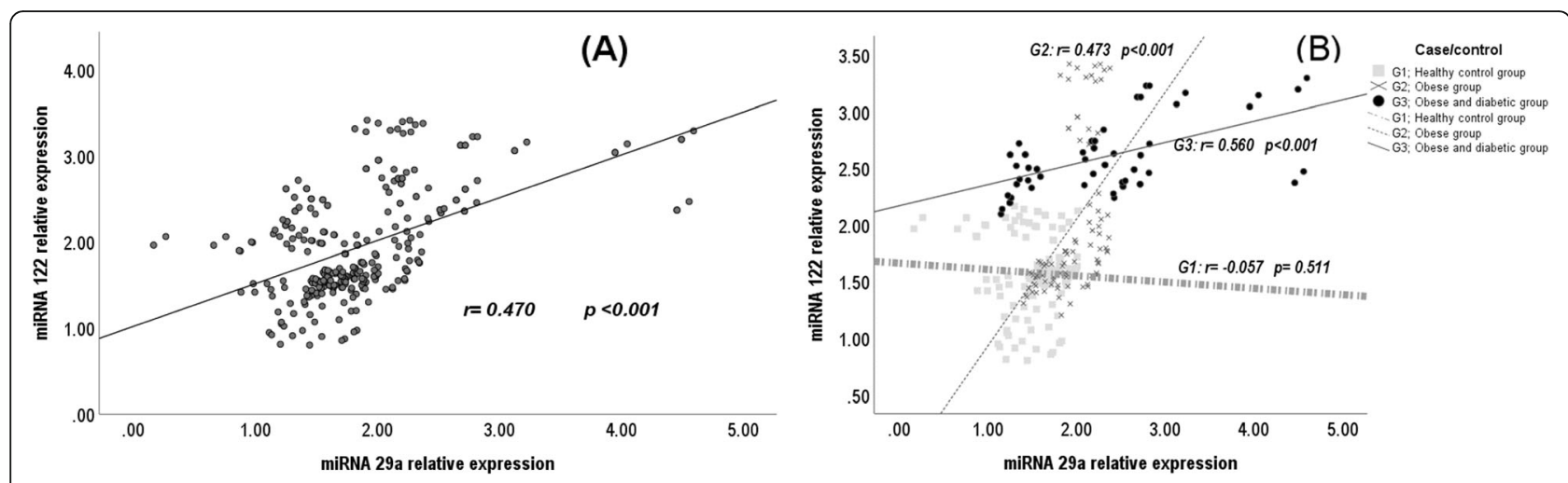

Fig. 1 Correlations of microRNA-29a relative expressions and microRNA-122 relative expressions: (A) in the whole sample, and (B) in G1, G2 and $\mathrm{G} 3$ 


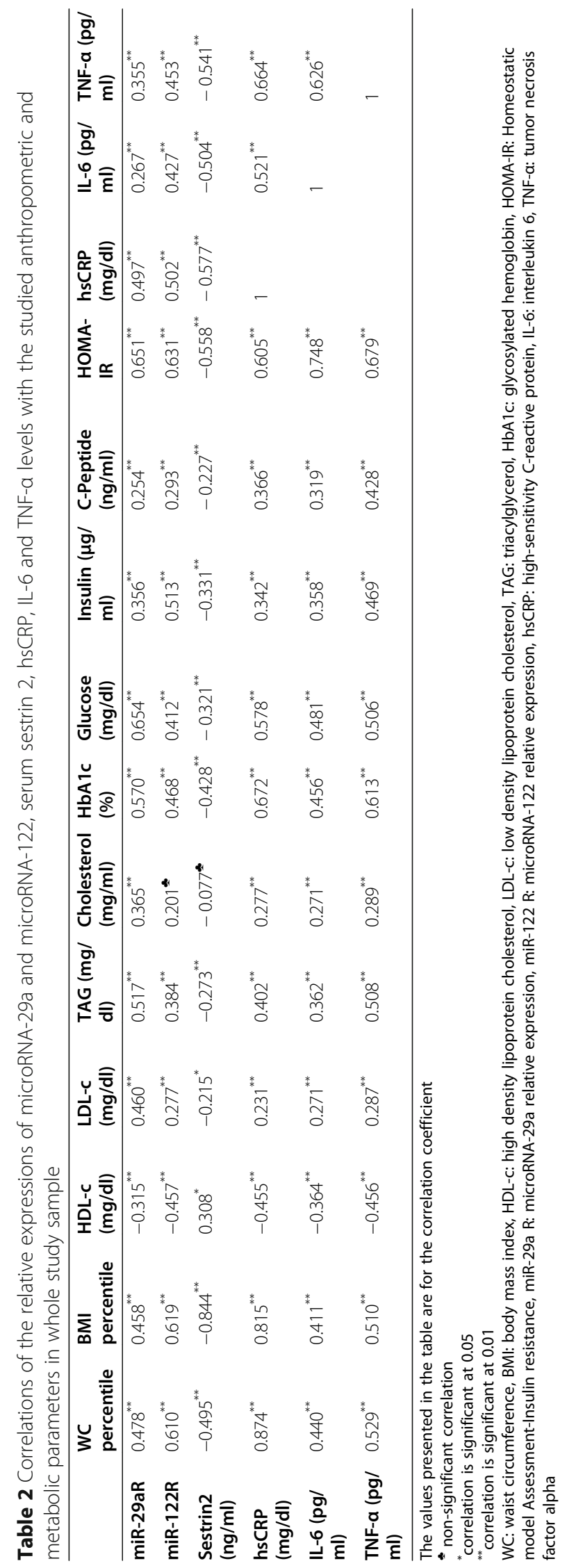




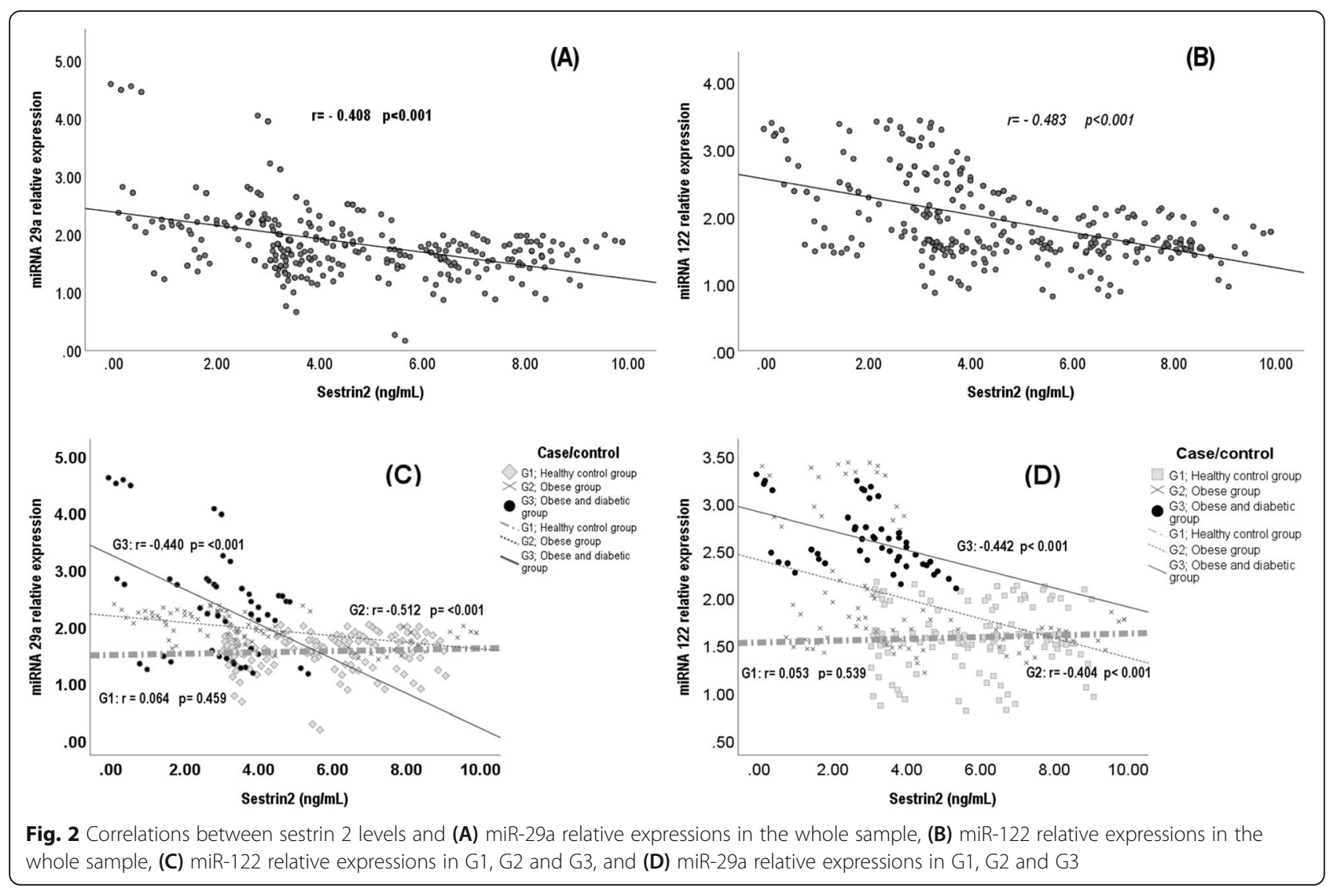

with serum levels of IL- 6 and TNF- $\alpha$ while negatively correlated with the serum levels HDL-cholesterol. The serum levels of IL- 6 correlated positively with BMI percentile and with the serum levels of TNF- $\alpha$ (Table 3).

\section{In obese group (G2)}

The serum levels of miR-29a and miR-122 correlated positively with WC percentiles, BMI percentiles, HOMA-IR and with serum levels of glucose, hsCRP, IL-6 and TNF- $\alpha$ (Table 3 ) and negatively with serum HDL-cholesterol (Table 3) and sestrin2 levels (Fig. 2C and D). Also, the serum levels of miR-122 correlated positively with the serum levels of triacylglycerol, total cholesterol and HbA1c\% (Table 3). In addition, serum levels of miR-122 and miR-29a correlated positively with each other (Fig. 1B). Moreover, the serum levels of hsCRP, IL- 6 and TNF- $\alpha$ correlated positively with WC percentiles, BMI percentiles, HOMA-IR and with serum levels of glucose and negatively with serum levels of HDL-cholesterol (Table 3). On the other hand, serum sestrin2 levels correlated negatively with WC percentiles, BMI percentiles, HOMA-IR and with serum levels of glucose, hsCRP, IL- 6 and TNF- $\alpha$ while positively with serum levels of HDL-cholesterol (Table 3).

\section{In obese with T2DM group (G3)}

The levels of serum miR-29a, miR-122, hsCRP, IL-6 and TNF- $\alpha$ levels correlated positively, while serum sestrin2 levels correlated negatively with WC percentiles and BMI percentiles, and serum levels of LDL-cholesterol, triacylglycerols, $\mathrm{HbA} 1 \mathrm{c} \%$, glucose, insulin, c-peptide and with HOMA-IR (Table 3). Also, the serum miR-29a and miR-122 levels correlated positively with each other (Fig. 1B) and with serum hsCRP, IL- 6 and TNF- $\alpha$ levels (Table 2). On the other hand, serum sestrin2 levels correlated negatively with the levels of miR-29a and miR122 (Fig. 2C and D) and with the levels of hsCRP, IL-6 and TNF- $\alpha$ (Table 3).

\section{Discussion}

The significant high levels of the miR-29a, miR-122, IL6 , hsCRP and TNF- $\alpha$ and the low levels of sestrin 2 that were found in obese children with/without T2DM emphasizes that chronic inflammation is a characteristic feature of childhood obesity with/without T2DM [7-10]. Previous studies had reported that the excessive accumulation of fat in the adipocytes leads to the activation of the resident immune cells and initiates a chronic immune-inflammatory process that results in the development of adverse metabolic consequences [15]. Significant increased levels of IL-6, CRP and TNF- $\alpha$ were 
|

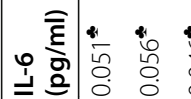

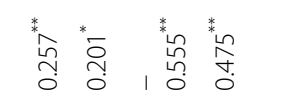

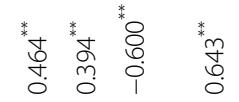

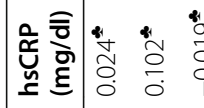

*a)

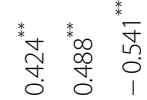

离

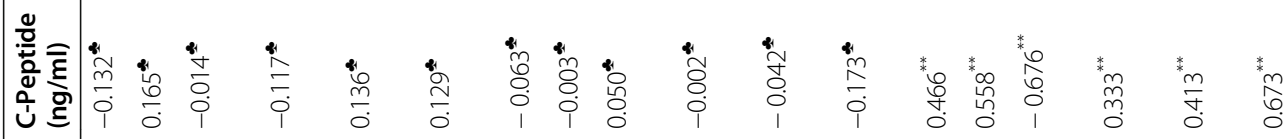

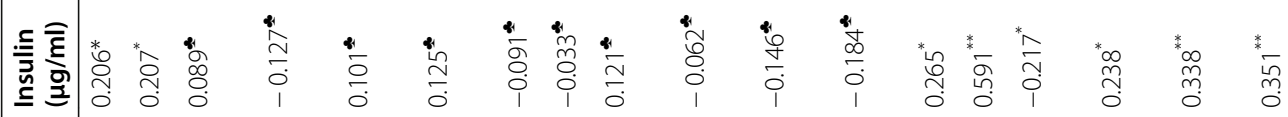

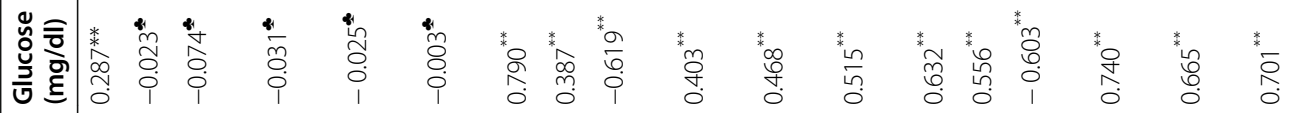

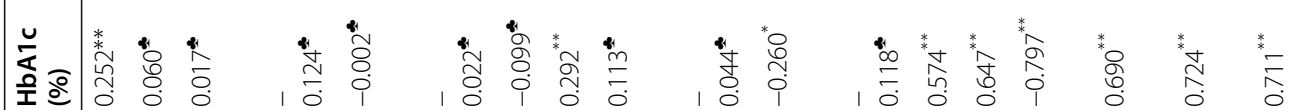

은

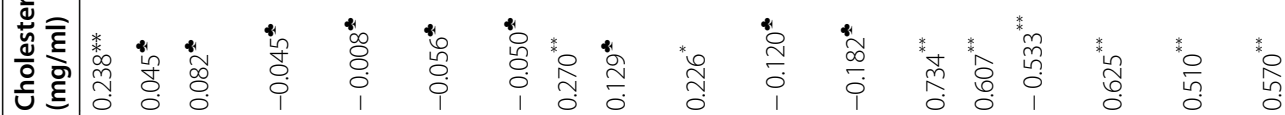

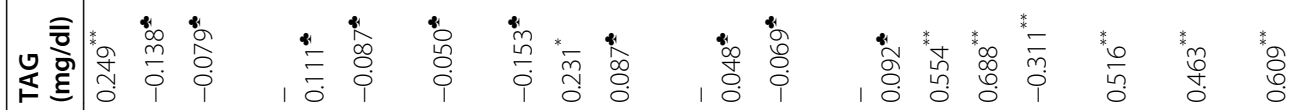

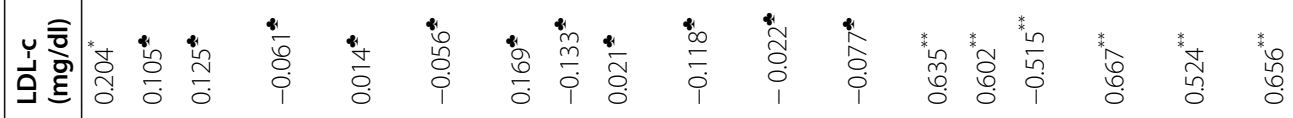

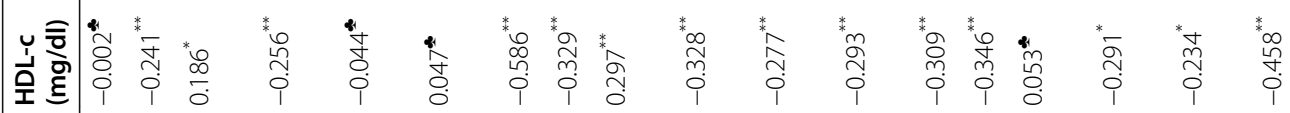

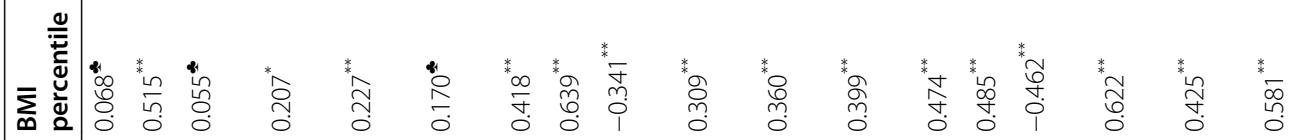

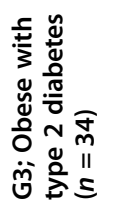


found by many studies in obese participants compared to the non-obese controls [7, 25, 26]. Also, increased levels of TNF- $\alpha$ and IL- 6 along with other proinflammatory cytokines were found in obese children and adolescents with insulin resistance and/or T2DM [25]. The proinflammatory cytokines may induce insulin resistance through unrestrained production of insulin receptor substrate [26].

MicroRNAs play a pivotal role in the modulation and progress of obesity related complications [15]. They have a well-known impact on the oxidant-antioxidant balance, lipid metabolism, and insulin action [27]. Also, they are involved in the development of insulin resistance and the development of T2DM through their effect on the insulin signaling pathway $[13,28]$. Moreover, microRNAs act as fine-control signal regulators for inflammatory processes through targeting the expression of the pro-inflammatory and anti-inflammatory genes in the immune cells [29].

In this regard the results of the current study are in accordance with the results of the study conducted by Pandey et al. [2011] who found an increased expression of miR-29a in the $\mathrm{db} / \mathrm{db}$ mice and this overexpression attenuates the insulin action [30]. Also, they go with the findings of Tang et al. [2017] who reported an ability of miR-29a to enhance the production pro-inflammatory mediators such as IL- 6 by targeting the protein kinase $\mathrm{B} /$ nuclear factor kappa beta pathway [14].

MiR-29a can downregulate the peroxisome proliferator-activated receptor delta (PPAR $\delta$ ) in skeletal muscles, which decreases the expression glucose transporter-4 (GLUT-4) and so the insulin dependent glucose entry to the cell [28]. Also, it prevents the repression of phospheneolpyruvare carboxykinase gene by insulin resulting in enhanced gluconeogenesis and marked increase in blood glucose levels [30]. Yang et al. [2014] found that the diet rich in saturated fatty acids resulted in an overexpression of miR-29a which led to a repression in the insulin receptor substrate 1 (IRS-1) and eventually to insulin resistance with decrease in cellular glucose uptake. This repression occurs via the direct binding of the miR-29a to the $3^{\prime}$ untranslated regions of IRS-1 mRNAs [31].

Contrary to the results of the present study, Iacomino and Siani [2017], and Ortega et al. [2014] found a nonsignificant difference in the miR-29a expression between obese and normal weight individuals [11, 32].

Another microRNA studied in the current work is miR-122. It is an abundant microRNA in the liver and accounts for more than $75 \%$ of the total hepatic microRNAs expression [33]. It regulates lipid metabolism (e.g. lipogenesis, cholesterol and VLDL synthesis) through its action on hepatocyte nuclear factor $4 \alpha(\mathrm{HNF}-4 \alpha)[33,34]$.
The results of the current study are in agreement with many of the previous studies. Yang et al. [2012] reported that the downregulation in miR-122 induces the protein tyrosine phosphatase $1 \beta$ which phosphorylates and inactivates HNF-4 $\alpha$ resulting in insulin resistance [35]. Jones et al. [2017] observed a positive correlation between miR-122 and insulin resistance and the amount of subcutaneous fat. They concluded that miR-122 might be a good marker for obesity and its related metabolic consequences [36]. Wang et al. [2015] found a 3.07-fold increase in the serum levels of miR-122 of obese patients when compared to healthy non-obese controls and these levels correlated positively with the BMI, serum levels of triacylglycerols, and HOMA-IR. Up on these findings, they suggested a possible role of miR-122 in the pathogenesis of obesity and insulin resistance [37]. Ortega et al. [2010] reported significant high levels of miR-122 in obese participants compared to those with normal weight and these levels decreased markedly after induction of weight loss surgically by gastric bypass operation [38].

Also, the results of the present work are in accordance with the results of Prats-Puig et al. [2013] who found significant high levels of miR-122 in obese children compared to non-obese children. They also observed significant positive correlations between miR-122 levels and BMI, WC, triacylglycerols, LDL and HOMA-IR [39]. In addition, the results work in with the findings of de Candia et al. [2017] who found a significant elevation of miR-122 in patients with impaired glucose tolerance compared to the healthy control group [40]. Moreover, Willeit et al. [2017] revealed significant high levels of miR-122 in adults with T2DM and these levels correlated positively with $\mathrm{BMI}, \mathrm{WC}$, triacylglycerols, hsCRP and HOMA-IR [41]. Indeed, miR-122 has been accused in the pathogenesis of many aspects of metabolic syndrome such as T2DM, hypertension, atherosclerosis and even, heart failure [42, 43].

The positive correlations between circulating miR-122 levels and IL-6, hsCRP and TNF- $\alpha$ agree with Song et al. [2020] and Zhao et al. [2020] who concluded that miR122 controls many immune-inflammatory processes including autophagy, programmed cell death and oxidative stress [43, 44]. Also, go with Wang et al. [2019] who found a significant decrease in the macrophages number and the levels of TNF- $\alpha$ in miR-122 knockout mice [45].

Sesrtins are inducible proteins that protect the cell during stress and inflammatory conditions by enhancing the cellular energy production and stimulation of the genome repair system [18, 46, 47]. Also, they get rid of reactive oxygen species either directly by acting on peroxiredoxins (antioxidant enzymes) or indirectly by regulating the expression of antioxidant genes (e.g. NrF2) [46]. Moreover, sestrins control numerous points in 
cellular metabolism by their ability to activate the AMPdependent protein kinase (AMPK) and inactivation of the mammalian target of rapamycin (mTOR) [18, 46, 48]. The inactivation of mTOR markedly decreases the cellular proteins and lipids synthesis and improves the insulin sensitivity by induction of phosphalidyl inositol3-kinase enzyme (PI3K) [46, 49].

The results of the current work agree with the results of Mohany and Al Rugaie [2020] who found significant lower levels of serum sestrin2 in patients with T2DM than the healthy control group [50]. Also, they agree with Sundararajan et al. [2020] who reported low serum sestrins levels in patients with dyslipidemia and T2DM and these levels correlated negatively with atherogenic factors and the severity of atherogenic index [51]. Moreover, Nourbakhsh et al. [2017] found significant lower levels of sestrin 2 in obese than the non-obese participants [19]. Insulin upregulates intracellular sestrin2 content and decreases its degradation through PI3K/mTOR signaling pathway [52]. Lack of normal cellular response to insulin in obese children with T2DM might explain the low sestrin2 levels and their negative correlations with HOMA-IR.

The negative correlations that were found in the present work between serum sestrin 2 levels and the levels of miR-29a and microR-122 reveals the complex nature of the pathogenesis of obesity, T2DM and their accompanied inflammations.

On contrary to the results of the current work, some previous studies reported significant high serum levels of sestrin 2 in obesity with/without T2DM but still showed significant positive correlations with BMI, serum levels of insulin, and HOMA-IR [20]. Also, sestrin 2 in the mice liver was found to be upregulated in obese mice feed on high fat diet [18]. The present study couldn't explain this inconsistency.

In conclusion, the change in the serum miR-29a, miR122 and sestrin2 levels in obese children with/without T2DM may suggest a possible role of these biomarkers in the pathogenesis of childhood obesity and their accompanied complications e.g. inflammations and type 2 diabetes mellitus.

\section{Recommendation}

Further studies are required to test the role of miRNAs and sestrin 2 in the pathogenesis of obesity and T2DM and their accompanied inflammation. To prevent these inflammations and other obesity related complications, drugs that antagonize the action miR-29a and miR-122 or upregulate sestrin2 levels should be tested.

\section{Abbreviations}

RNA: ribonucleic acid; T2DM: type 2 diabetes mellitus; IL-6: interleukin-6; hsCRP: high sensitivity C-reactive protein; TNF-a: tumor necrosis factor alpha; WC: waist circumference; BMI: body mass index; ELISA: enzyme-linked immunosorbent assay; HbA1c\%: glycosylated hemoglobin percentage; HDLc: high density lipoproteins cholesterol; LDLc: low density lipoproteins cholesterol; HOMA-IR: homeostasis model assessment of insulin resistance; cDNA: complementary deoxyribonucleic acid; SPSS: statistical package for the social sciences; PPAR: peroxisome proliferator-activated receptor; PI3K: phosphalidyl inositol-3-kinase enzyme; Glut-4: glucose transporter-4; IRS-1: insulin receptor substrate-1; HNF-4a: hepatocyte nuclear factor - 4 alpha

\section{Supplementary Information}

The online version contains supplementary material available at https://doi. org/10.1186/s12902-021-00829-z

Additional file 1

\section{Acknowledgments}

The authors gratefully acknowledge Qassim University, represented by the deanship of scientific research on the material support of this research under the number mduc-2019-2-2-|-5441.

Authors' contributions

KMM (Conception, design of the work, the acquisition of the data, analysis of the data, interpretation of data; drafted the work and substantially revised it), OAlr (Conception, design of the work, drafted the work and substantially revised it), OA (Conception, analysis of the data, interpretation of data, substantially revised it), and $\mathrm{AA}$ (Conception, design of the work, the acquisition of the data, substantially revised it). The authors read and approved the final manuscript.

\section{Funding}

This study was funded by Qassim University, represented by the deanship of scientific research (mduc-2019-2-2-|-5441).

Availability of data and materials

The datasets used and/or analyzed during the current study are available from the corresponding author on reasonable request. The sequences of miRNA-29a, - 122 and 39 are available @www.mirbase.org

\section{Declarations}

Ethics approval and consent to participate

The present work was conducted in three primary health care centers in Unaizah governorate, Qassim area, Kingdom of Saudi Arabia. It was reviewed and approved by the Qassim University medical research committee (approval\# mduc-2019-2-2-1-5441). All procedures performed in the study were in accordance with the 1964 Helsinki declaration and its later amendments or comparable ethical standards. Informed consents were obtained from the parents of all children included in the study.

Consent for publication

not applicable.

\section{Competing interests}

The authors declare that they have no competing interests

\section{Author details}

${ }^{1}$ Department of Medical Biochemistry, College of Medicine, Assiut University, P.O. Box, Assiut 71515, Egypt. ${ }^{2}$ Department of Basic Medical Sciences, Unaizah College of Medicine and Medical Sciences, Qassim University, Unaizah, Saudi Arabia. ${ }^{3}$ Department of Family and Community Medicine, Unaizah College of Medicine and Medical Sciences, Qassim University, Unaizah, Saudi Arabia. ${ }^{4}$ Department of Pediatrics, Unaizah College of Medicine and Medical Sciences, Qassim University, Unaizah, Saudi Arabia. 


\section{Received: 24 March 2021 Accepted: 13 July 2021}

\section{Published online: 03 August 2021}

\section{References}

1. NCD Risk Factor Collaboration (NCD-RisC). Worldwide trends in body-mass index, underweight, overweight, and obesity from 1975 to 2016: a pooled analysis of 2416 population-based measurement studies in 128.9 million children, adolescents, and adults. Lancet. 2017;390(10113):2627-42. https:// doi.org/10.1016/S0140-6736(17)32129-3.

2. Blüher M. Obesity: global epidemiology and pathogenesis. Nat Rev Endocrinol. 2019;15(5):288-98. https://doi.org/10.1038/s41574-019-0176-8.

3. World Health Organization (WHO). Country Cooperation Strategy for WHO and Saudi Arabia 2012-2016. 2013. Retrieved from http://www.who.int/ countryfocus/cooperation_strategy/ccs_sau_en.pdf.

4. Al Dhaifallah A, Mwanri L, Aljoudi A. Childhood obesity in Saudi Arabia: opportunities and challenge. Saudi Journal of obesity. 2015;3(1):2-7.

5. Cui $X$, You L, Zhu L, Wang $X$, Zhou Y, Wen J, et al. Change in circulating miR profile of obese children indicates future risk of adult diabetes. Metab Clin Exp. 2018;78:95-105. https://doi.org/10.1016/.metabol.2017.09.006.

6. Weintrob N, Stern E, Klipper-Aurbach Y, Phillip M, Gat-Yablonski G. Childhood obesity complicating the differential diagnosis of maturity-onset diabetes of the young and type 2 diabetes. Pediatr Diabetes. 2008;9(1):60-4 https://doi.org/10.1111/j.1399-5448.2007.00259.x.

7. Ellulu MS, Patimah I, Khaza'ai H, Rahmat A, Abed Y. Obesity and inflammation: the linking mechanism and the complications. Arch Med Sci. 2017;13(4):851-63. https://doi.org/10.5114/aoms.2016.58928.

8. Donath MY, Shoelson SE. Type 2 diabetes as an inflammatory disease. Nat Rev Immunol. 2011;11(2):98-107. https://doi.org/10.1038/nri2925.

9. Wolowczuk I. Obesity-an inflammatory state. Acta Vet Scand. 2015;57(1):K5. https://doi.org/10.1186/1751-0147-57-S1-K5.

10. Carolan E, Hogan AE, Corrigan M, Gaotswe G, O'Connell J, Foley N, et al. The impact of childhood obesity on inflammation, innate immune cell frequency, and metabolic miR expression. J Clin Endocrinol Metab. 2014; 99(3):E474-8. https://doi.org/10.1210/jc.2013-3529.

11. lacomino $\mathrm{G}$, Siani A. Role of miRs in obesity and obesity-related diseases. Genes Nutr. 2017;12(1):23. https://doi.org/10.1186/s12263-017-0577-z.

12. Mohany KM, Al Rugaie $O$, Al-wutayd O, Al-Nafeesah A, Saleem TH. Association between circulating miRs 486, 146b and 15b and serum betatrophin levels in obese; type 2 diabetic and non-diabetic children. BMC Endocr Disord. 2020;20(1):145.

13. Feng J, Xing W, Xie L. Regulatory roles of MiRs in diabetes. Int J Mol Sci. 2016;17(10):1729. https://doi.org/10.3390/ijms17101729.

14. Tang B, Li X, Ren Y, Wang J, Xu D, Hang Y, et al. MiR-29a regulates lipopolysaccharide (LPS)-induced inflammatory responses in murine macrophages through the Akt1/ NF-kB pathway. Exp Cell Res. 2017;360(2): 74-80. https://doi.org/10.1016/j.yexcr.2017.08.013.

15. Zhong H, Ma M, Liang T, Guo L. Role of MiRs in obesity-induced metabolic disorder and immune response. J Immunol Res. 2018;Article ID 2835761:8 https://doi.org/10.1155/2018/2835761.

16. Shah R, Murthy $V$, Pacold M, Danielson K, Tanriverdi K, Larson MG, et al. Extracellular RNAs are associated with insulin resistance and metabolic phenotypes. Diabetes Care. 2017;40(4):546-53. https://doi.org/10.2337/dc1 6-1354.

17. Sendi H, Mead I, Wan M, Mehrab-Mohseni M, Koch K, Atala A, et al. miR-122 inhibition in a human liver organoid model leads to liver inflammation, necrosis, steatofibrosis and dysregulated insulin signaling. PLoS One. 2018; 13(7):e0200847.

18. Lee JH, Budanov AV, Talukdar S, Park EJ, Park HL, Park HW, et al. Maintenance of metabolic homeostasis by Sestrin2 and Sestrin3. Cell Metab. 2012;16(3):311-21. https://doi.org/10.1016/j.cmet.2012.08.004.

19. Nourbakhsh M, Sharifi R, Ghorbanhosseini SS, Javad A, Ahmadpour F, Razzaghy Azar M, et al. Evaluation of plasma TRB3 and Sestrin 2 levels in obese and Normal-weight children. Child Obes. 2017;13(5):409-14. https:// doi.org/10.1089/chi.2017.0082.

20. Chung HS, Hwang HJ, Hwang SY, Kim NH, Seo JA, Kim SG, et al. Association of serum Sestrin 2 level with metabolic risk factors in newly diagnosed drug-naïve type 2 diabetes. Diabetes Res Clin Pract. 2018;144:34-41. https:// doi.org/10.1016/j.diabres.2018.07.024.

21. Temneanu OR, Trandafir LM, Purcarea MR. Type 2 diabetes mellitus in children and adolescents: a relatively new clinical problem within pediatric practice. J Med Life. 2016;9(3):235-9.
22. Friedwald WT, Levy RI, Fredrickson DS. Estimation of the concentration of LDL-C in plasma without use of the preparative ultracentrifuge. Clin Chem. 1972;18:449-502.

23. Matthews DR, Hosker JP, Rudenski AS, Naylor BA, Treacher DF, Turner RC. Homeostasis model assessment: insulin resistance and beta-cell function from fasting plasma glucose and insulin concentrations in man. Diabetologia. 1985;28(7):412-9. https://doi.org/10.1007/BF00280883.

24. Lim LP, Glasner ME, Yekta S, Burge CB, Bartel DP. Vertebrate microRNA genes. Science. 2003;7;299(5612):1540.

25. Reinehr T. Inflammatory markers in children and adolescents with type 2 diabetes mellitus. Clin Chim Acta. 2019;496:100-7. https://doi.org/10.1016/j. cca.2019.07.006.

26. Smitka K, Maresova D. Adipose tissue as an endocrine organ: an update on pro-inflammatory and anti-inflammatory microenvironment. Prague Med Rep. 2015;116(2):87-111. https://doi.org/10.14712/23362936.2015.49.

27. Marques-Rocha JL, Samblas M, Milagro Fl, Bressan J, Martínez JA, Marti A. Noncoding RNAs, cytokines, and inflammation-related diseases. FASEB J. 2015;29(9):3595-611. https://doi.org/10.1096/fj.14-260323.

28. Zhou Y, Gu P, Shi W, Li J, Hao Q, Cao X, et al. MiR-29a induces insulin resistance by targeting PPARS in skeletal muscle cells. Int J Mol Med. 2016; 37(4):931-8. https://doi.org/10.3892/ijmm.2016.2499.

29. Tahamtan A, Teymoori-Rad M, Nakstad B, Salimi V. Anti-inflammatory MiRs and their potential for inflammatory diseases treatment. Front Immunol. 2018;9:1377. https://doi.org/10.3389/fimmu.2018.01377.

30. Pandey AK, Verma G, Vig S, Srivastava S, Srivastava AK, Datta M. miR-29a levels are elevated in the $\mathrm{db} / \mathrm{db}$ mice liver and its overexpression leads to attenuation of insulin action on PEPCK gene expression in HepG2 cells. Mol Cell Endocrinol. 2011;332(1-2):125-33. https:/doi.org/10.1016/j.mce.2010.10.004.

31. Yang WM, Jeong HJ, Park SY, Lee W. Induction of miR-29a by saturated fatty acids impairs insulin signaling and glucose uptake through translational repression of IRS-1 in myocytes. FEBS Lett. 2014;588(13):2170-6. https://doi. org/10.1016/j.febslet.2014.05.011.

32. Ortega FJ, Mercader JM, Moreno-Navarrete JM, Rovira O, Guerra E, Esteve E, et al. Profling of circulating miRs reveals common miRs linked to type 2 diabetes that change with insulin sensitization. Diabetes Care. 2014;37(5): 1375-83. https://doi.org/10.2337/dc13-1847.

33. Fernández-Hernando C, Ramírez CM, Goedeke L, Suárez Y. MiRs in metabolic disease. Arterioscler Thromb Vasc Biol. 2013;33(2):178-85. https:// doi.org/10.1161/ATVBAHA.112.300144.

34. De Rosa S, Arcidiacono B, Chiefari E, Brunetti A, Indolfi C, Foti DP. Type 2 diabetes mellitus and cardiovascular disease: genetic and epigenetic links. Front Endocrinol (Lausanne). 2018;9:2. https://doi.org/10.3389/fendo.2018. 00002.

35. Yang YM, Seo SY, Kim TH, Kim SG. Decrease of miR-122 causes hepatic insulin resistance by inducing protein tyrosine phosphatase $1 \mathrm{~B}$, which is reversed by licorice flavonoid. Hepatology. 2012;56(6):2209-20. https://doi. org/10.1002/hep.25912.

36. Jones A, Danielson KM, Benton MC, Ziegler O, Shah R, Stubbs RS, et al. miRNA signatures of insulin resistance in obesity. Obesity. 2017;25(10):173444. https://doi.org/10.1002/oby.21950.

37. Wang R, Hong J, Cao Y, Shi J, Gu W, Ning G, et al. Elevated circulating miR122 is associated with obesity and insulin resistance in young adults. Eur J Endocrinol. 2015;172(3):291-300. https://doi.org/10.1530/EJE-14-0867.

38. Ortega FJ, Moreno-Navarrete JM, Pardo G, Sabater M, Hummel M, Ferrer A, et al. MiRNA Expression Profile of Human Subcutaneous Adipose and during Adipocyte Differentiation. PLoS One. 2010;5(2):e9022.

39. Prats-Puig A, Ortega FJ, Mercader JM, Moreno-Navarrete JM, Moreno M, Bonet $\mathrm{N}$, et al. Changes in circulating miRs are associated with childhood obesity. J Clin Endocrinol Metab. 2013;98(10):E1655-60. https://doi.org/1 $0.1210 / j c .2013-1496$

40. de Candia P, Spinetti G, Specchia C, Sangalli E, La Sala L, Uccellatore A, et al. A unique plasma miR profile defines type 2 diabetes progression. PLoS One. 2017;12(12):e0188980. https://doi.org/10.1371/journal.pone.0188980.

41. Willeit P, Skroblin P, Moschen AR, Yin X, Kaudewitz D, Zampetaki A, et al. Circulating miR-122 is associated with the risk of new-onset metabolic syndrome and type 2 diabetes. Diabetes. 2017;66(2):347-57. https://doi. org/10.2337/db16-0731.

42. Zhang HN, Xu QQ, Thakur A, Alfred MO, Chakraborty M, Ghosh A, et al. Endothelial dysfunction in diabetes and hypertension: role of miRs and long non-coding RNAs. Life Sci. 2018;213:258-68. https://doi.org/10.1016/j.lfs.201 8.10.028. 
43. Song JJ, Yang M, Liu Y, Song JW, Wang J, Chi HJ, et al. MiR-122 aggravates angiotensin II-mediated apoptosis and autophagy imbalance in rat aortic adventitial fibroblasts via the modulation of SIRT6-elabela-ACE2 signaling. Eur J Pharmacol. 2020;883:173374. https://doi.org/10.1016/j.ejphar.2020.1733 74.

44. Zhao Z, Zhong L, Li P, He K, Qiu C, Zhao L, et al. Cholesterol impairs hepatocyte lysosomal function causing M1 polarization of macrophages via exosomal miR-122-5p. Exp Cell Res. 2020;387(1):111738. https://doi.org/10.1 016/j.yexcr.2019.111738.

45. Wang $Y$, Liang $H$, Jin $F$, Yan $X, X u G, H u H$, et al. Injured liver-released miRNA-122 elicits acute pulmonary inflammation via activating alveolar macrophage TLR7 signaling pathway. Proc Natl Acad Sci U S A. 2019; 116(13):6162-71. https://doi.org/10.1073/pnas.1814139116.

46. Lee JH, Budanov AV, Karin M. Sestrins orchestrate cellular metabolism to attenuate aging. Cell Metab. 2013;18(6):792-801. https://doi.org/10.1016/j. cmet.2013.08.018.

47. Sun $W$, Wang $Y$, Zheng $Y$, Quan N. The emerging role of Sestrin 2 in cell metabolism, and cardiovascular and age-related diseases. Aging Dis. 2020; 11(1):154-63. https://doi.org/10.14336/AD.2019.0320.

48. Ro SH, Xue X, Ramakrishnan SK, Cho CK, Namkoong S, Jang I, et al. Tumo suppressive role of sestrin2 during colitis and colon carcinogenesis. eLife. 2016:5:e12204

49. Wullschleger S, Loewith R, Hall MN. TOR signaling in growth and metabolism. Cell. 2006;124(3):471-84. https://doi.org/10.1016/j.cell.2006.01.01 6.

50. Mohany KM and Al Rugaie. Association of serum sestrin 2 and betatrophin with serumneutrophil gelatinase associated lipocalin levels in type 2 diabetic patients with diabetic nephropathy. J Diabetes Metab Disord. 2020; 6;19(1):249-256.

51. Sundararajan S, Jayachandran I, Subramanian SC, Anjana RM, Balasubramanyam M, Mohan V, et al. Decreased Sestrin levels in patients with type 2 diabetes and dyslipidemia and their association with the severity of atherogenic index. J Endocrinol Investig. 2020. https://doi.org/1 0.1007/s40618-020-01429-9;44(7):1395-405.

52. Chai D, Wang G, Zhou Z, Yang H, Yu Z. Insulin Increases Sestrin 2 Content by Reducing Its Degradation through the PI $3 \mathrm{~K} / \mathrm{mTOR}$ Signaling Pathway. Int J Endocrinol. 2015;2015:505849. https://doi.org/10.1155/2015/505849 Epub 2015 Feb 22. PMID: 25792980; PMCID: PMC4352509.

\section{Publisher's Note}

Springer Nature remains neutral with regard to jurisdictional claims in published maps and institutional affiliations.

Ready to submit your research? Choose BMC and benefit from:

- fast, convenient online submission

- thorough peer review by experienced researchers in your field

- rapid publication on acceptance

- support for research data, including large and complex data types

- gold Open Access which fosters wider collaboration and increased citations

- maximum visibility for your research: over $100 \mathrm{M}$ website views per year

At BMC, research is always in progress.

Learn more biomedcentral.com/submissions 